مجلة جامعة سبها للعلوم البحتة والتطبيقية

Sebha University Journal of Pure \& Applied Sciences

Journal homepage: www.sebhau.edu.ly/journal/index.php/jopas

\title{
Condition monitoring of Electrical Submersible Pumps (Faults review)
}

Salem. A. Al-Hashmi

Department of Electronic and electrical engineering, Faculty of Engineering \& Technology, Sebha University, Libya Authority of Natural Science Research and Technology

\section{Keywords:}

Broken Rotor

Stator turn

Bearin

Impeller entrance

Diffuser

\begin{abstract}
A B S T R A C T
This paper is a part of condition monitoring of electrical submersible pumps (ESP). It assigned for reviewing and discussing faults or malfunctions of this kind of pumps. Therefore, it reviews allimportant information related to this machine such as construction and operation. It focuses specifically on faults and details of these types of fault. Although there are slight differences between building submersible pumps in terms of the different technologies that different manufacturers use in making this type of pump, all kinds of these types of pumps are almost the same. In this context, pumps faults were reviewed based on major and common failures of this type of pumps.
\end{abstract}

مر اقبة المضخات الغاطسـة الكهربائية ( حصروو مراجعة الاعطال)

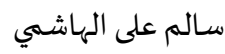

$$
\text { هيئة ابحم الهندسة العهربائية والالكترونية، كلية العلوم الهندسية والتقنية، جامعة سبها، ليبيا }
$$

ملفات الجزء الكلمات الندات المفتاحية:

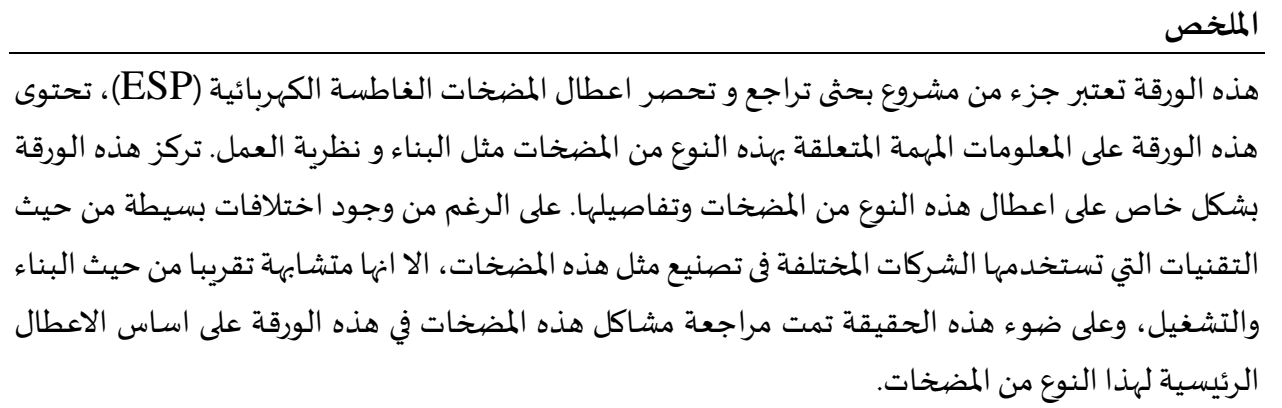

\section{Introduction}

The electrical submersible pumps (ESP) play a significant and vital role in many applications, such as; industries, agriculture and providing drinking water for modern and rural communities. Failure in the functioning modes of ESP results in unplanned downtime, which costs many money and stop vital services [1-4], therefore monitoring, collecting data, analyzing this data and detecting any potential fault is very important task.

It is important here to mention here that centrifugal is the definition of the operation way of the pump, whereas Submersible is the definition of where the pump is placed during it operation. Therefore, a submersible pump can be of a centrifugal type (most of them are) $[5,6]$. A submersible pump means that the pump is placed under water, like in a well. This allows the pump to be operating at all the variable water levels that the well can experience. There will be no problems of suction heights and no need to prime or install a foot valve. The only selection criteria will be the maximum static pressure it can develop at the output side, and the flow rate to achieve the required output at the required level [5]. In order to understand faults which may encounters the submersible pumps, it is crucial to study its construction and operation of this kind of pumps.

\section{SP construction}

This type of pumps driven by submersible motor (wet motor), it is very similar to a pump driven by a vertical spindle dry motor (traditional centrifugal pumps). Although, some differences between ordinary centrifugal pumps and submersible centrifugal pumps,

*Corresponding author:

E-mail addresses: sal.mana@sebhau.edu.ly 
submersible type gained in popularity because the usually result in a cheaper installation than one using dry motor [7]. Generally, all the pumps consist of two main components; pump and motor.

\section{Pump Construction}

As it's presented in figure 1 the submersible pump consists of:-

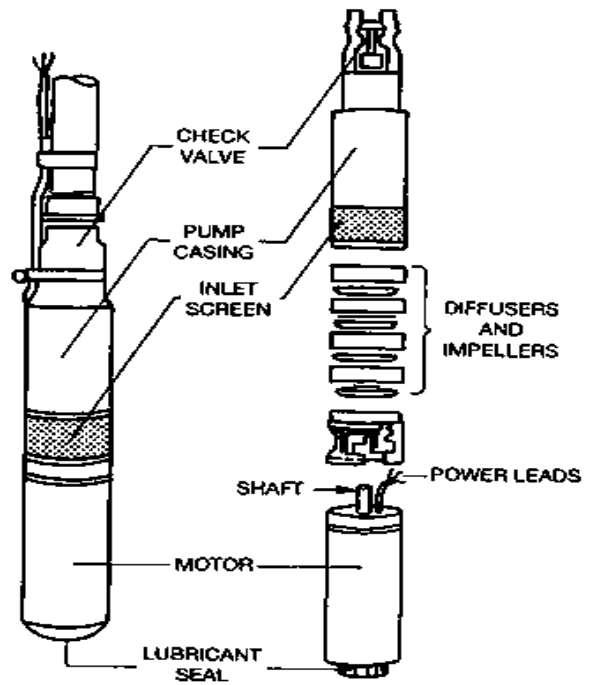

Figure 1, [8]
1- Head
2- Check valve
3- Pump casing
4- Inlet screen
5- Diffuser and impeller
6- Power leads
7- Shaft
8- Motor
9- Lubricating seal

\section{Motor}

The pump is rotates by a squirrel-cage induction motor. Induction motors are widely used in industry because of their durability, low production costs, and cheap maintenance $[9,10]$.

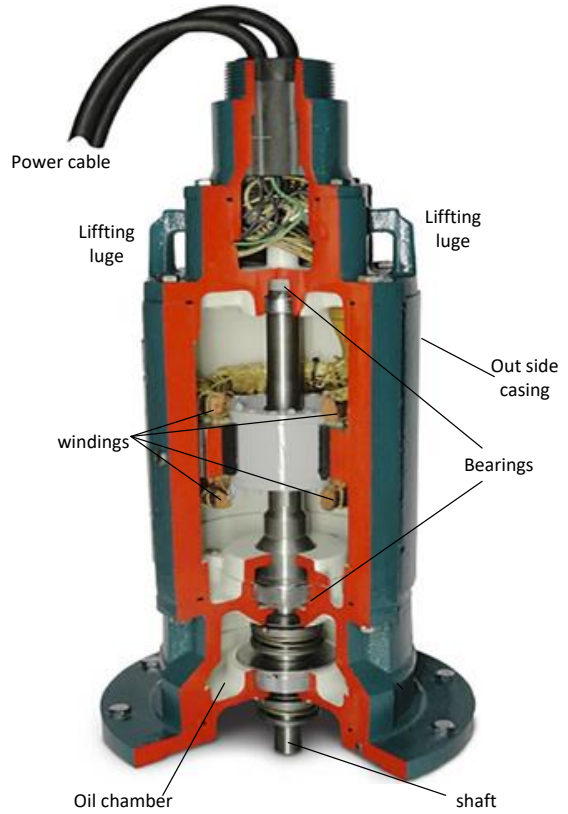

Figure 2: motor construction [11]
Although the working principles of submersible pump motors are same with traditional induction motors, it has some small differences in their structure, its diameter is limited to the size of wells drilled, most of submersible induction motors (SIMs) are designed to install in four or six inch wells, in some cases may be larger.

Increasing the motor power, achieved simply by extending the rotor length. Therefore, lengths of SIMs are longer than traditional induction motors, while its diameters are shorter[12, 13]. Figure 2 introduces a sample of a motor of submersible pump. As it is shown in the figure, 2 , it consists of stator windings, rotor cage, cable and cable connection, casing and the bearing.

\section{ESP operation}

The impeller on the shaft is rotated at a high speed by motor. Under the action of centrifugal force, the rotation sends the fluid in the impeller to the sides of the impeller along the blade between the flow channels. Because the blades force the liquid, its pressure and velocity increase at the same time. By additional action of the impeller, the velocity energy of the liquid is transformed into pressure energy and the liquid flows to the impeller entrance of the subsequent stage pump. After the liquid passes successively multistage impellers, the liquid flows onto the ground level where the liquid pressure successive increases enable it to overcome the pump, discharge and pipeline resistance. Due to the complex well environment and undefined impurities in the well liquid, such as sand, slurry, gas, and so on, it is almost impossible for the ESP to run in an ideal condition and the possibility of failure is high $[5,14]$.

\section{ESP faults}

Possible failures in any submersible pumping systems are classified according to the place of their occurrence and typical failures are: pump motors... etc. Further classifications of submersible pumps faults are; electrical or mechanical failures. It is important to mention that many mechanical faults cusec electrical fault, for example bearing failure cusses increasing the motor temperature, destroyed the winding insulation, hence stop the motor from running.

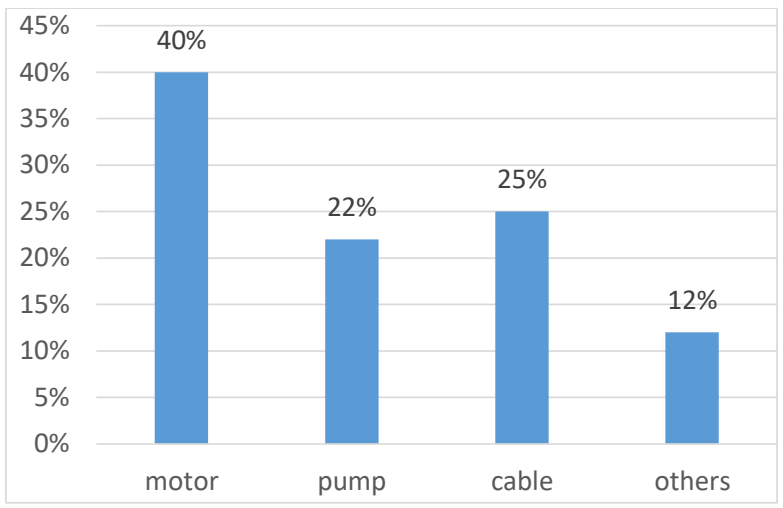

Figure 3: Reasons of ESP failures.[15]

Figure 3: motor failure possibilities

According to [15], the failure possible occurs in motor, pump, cables and others, see figure 3 .

It is clear from the figure that the motor faults dominants the other faults.

\section{Motor faults}

The study of failures in electric motors is an interest subject to the academic and industrial community, the trend research focuses on approaches, which are used to measure and identify faults by on-line or off-line tests. Among these researchers some authors have classified and grouped motor failures by the nature of the failure (electrical, mechanical), fault location (stator, rotor) [16, 17]. It is important to define the term of failure in an electrical machine. The 
failure is defined as how change in any component of the machine that prevents proper operation. It can be also defined as the unavailability of an element to perform an intended action [18]. In this meaning the steps of failure are: insipient of failure, material fatigue, deterioration and the fault itself. According [18] the main reasons of failures are categorized as:

$\checkmark \quad$ Inherent weakness of material, design and manufacturing.

$\checkmark \quad$ Misuse or application of efforts in the wrong direction.

$\checkmark \quad$ The gradual deterioration because of wear, tear and fatigue by stress or corrosion.

Publications [9, 19] indicated that the motor failures distribution percentage in electric motors is approximately: $45 \%$ in the bearings, $35 \%$ in the stator, $10 \%$ in the rotor and the remaining $10 \%$ in other categories

\section{Rotor faults}

Since the rotor of submersible pump is squirrel cage type, its failure occurrence possibility is low compared with bearing and stator. Generally, the rotor failures are caused by electrical problems, in manufacturing defects or and breakage of bars. The defects connected with the bars has its origin mainly on thermal stress or fatigue product operating transients such as start-ups, this problem is usually related to high power motors. The second case is frequent mechanical problems such as misalignment of the motor or load variation $[16,20,21]$.

\section{Eccentricity}

The air gap eccentricity in rotating electrical machines is connected with a variation in the air gap between stator and rotor. It can be static, dynamic or mixed in nature[9]. Some reasons of this fault can be; bent shafts, wear on the bearings, excessive mechanical vibrations or resonances [16, 22, 23].

\section{Short turn}

According to many publications $[9,16,20], 35-40 \%$ of induction motor failures are result of stator winding insulation. Additionally, it is understood that a large portion of stator winding-related failures are initiated by insulation failures. The most frequent faults in the stator are short coil to coil, fault between phases, coil open circuit or ground phase. In a three-phase machine produces a large circulating current flowing in the shorted coils or turns. This circulating current generates heat which is proportional to the square of circulating current. If the it exceeds the limiting value it will completely destroyed the motor windings[9].

\section{Increasing temperature}

The submersible motor is affected by many faults, which causes over current hence over temperature, which cause insulation failure. Faults, which result in high temperature, are; reverse motor rotating, increasing the level of water to be greater than the potential energy of the pump, clogging of drag slot of the impeller, close the pump valve without notice and any electrical fault during connection. [22, 24].

\section{Pump faults}

pump geometry, operating condition and fluid properties all are factors may contribute to the wear mechanism of the impeller [15]. The main reason of most wear of pumps components is fluid properties, particularly, the fluid that contains sand. Production of sand or other abrasive solid materials along with the well fluid severely reduces the run life of regular ESP equipment, the most affected component being the impeller diffuser, and bearings [5, 15] Impeller flow path wear

As it mentioned above, erosion in pump components is initiated because of the abrasive solid particles striking the metal surface, exactly like in sandblasting. The wear caused is greater for large and rough solid particles than for small and smooth ones. In addition, wear is proportional to the square of flow velocity because the destructive potential of the solids is related to their kinetic energy. Because of the cushioning effect of the liquid phase the suspended solid particles do most of the damage at places or points where a change of flow direction takes place: at the entrances to the diffuser and to the impeller $[5,15]$.

\section{Diffuser wear}

The pump diffuse is an essential and important component of any submersible pump. Erosion occurs around the balance ring in the diffuser is another type of erosion, it occurs where solid particles are moved by viscous drag in the stagnant fluid. Though erosion of pump stages can be sizeable, it seldom causes failure, simply because the pump usually fails for other reasons long before it is completely eroded $[5,15]$.

\section{Bearing wear}

Bearings are the most affected component compared with other faults of induction motor, it is around $40 \%$, hence it's possibility is high [9, 16]. Radial and thrust wear is initiated by abrasion in the pump's radial and thrust bearings. In standard pumps, radial support of the pump shaft is provided by simple journal bearings with the impeller hub acting as the journal and the diffuser bore being the bearing. Journal and bearing materials are same as the materials of the stage with well fluid lubricating the two parts. These bearings run almost for the total length of the shaft and have fixed radial clearances, the amount of clearance depending on pump design and machining tolerances. Clearances are usually small but large enough for the majority of sand particles to arrive the space between the bearing and the journal. Larger and strong particles, after entering the clearance space, are crushed and remove metal from the surface of bearing. The amount of sand particles carried by the fluid increases as the flow rates increased, hence the amount of wear heavily increases as well [5].

\section{Seal wear}

The seal or protector, in normal situations works as safeguards of the electric motor, which is directly connected, to it. Seal failures be attributed to the subsequent reasons [5].

$\checkmark$ Broken or damaged mechanical seals leak well fluids into the protector and then into the motor; this may be produced by:-

\section{$\checkmark \quad$ Vibrations transferred from a worn pump, or}

$\checkmark$ Faulty equipment or improper installation.

$\checkmark \quad$ The pump's main thrust bearing positioned in the protector may fail when the pump operates in extreme up- or down thrust mode

\section{Conclusion}

The all possible faults and failures of submersible pumps are reviewed and discussed. The review come to a result that the motor failure is dominated the submersible system, it contributes with $40 \%$ of all total system faults. In context of motor failure, stator winding and bearing faults are responsible of around $35-40 \%$ of total motor faults each. Related to pump component, the main reason of most wear is the fluid properties, particularly the fluid which contains sand. The fluid which contains sand or other abrasive solid materials severely reduced the run life of the pump, it affected bearing, impeller and diffuser. It is noticeable that many motor faults connected to mechanical faults which result in increasing the motor temperature, break down the winding insulation hence winding faults.

\section{References}

[1]- M S Kovalchuk, D.A.P., Diagnosis of Electric Submersible Centrifugal pump, in Earth Environmental Science 2018, saint petersburg mining university: saint Petersburg.

[2]- $\mathrm{Lu} \mathrm{Li}$, c.H.X.X., condition monitoring and fault diagnosis of electrical submersible pump based on wellhead electrical paerameters and production parameters. system science \& control engineering, 2018. 6(3): p. 253 - 261. 
[3]- Bantelay, D.T., investigating water supply system electro mechanical equipment problems: a case study of ethiopia. journal of optimization in industrial engineering, 2019. 12(2): $\mathrm{p}$. 45-54.

[4]- abhay. Patil, A.d., Yi Chen, Daniel Steck, Chang-rui Bai, Yi ming Chen, Gerald Morrison, Mechanical Reliability of Electrical Submersible Pumps. chinese journal of turbomachinery, 2018. 60(5): p. 1.

[5]- G, T., Electrical submersible pumps manual. 2009: Gulf proffessional publishing.

[6]- Karassik, I.J., et al., Pump handbook. third edition ed. 2001: McGraw-Hill.

[7]- D, R., K, Michael Johanson, Pumping: Electrical Plant< Control and Instrumentation, 2009. p. 31.

[8]- UNHCR. Water Manual for Refugee Situations. 1992.

[9]- Thomas, S.B.a.V.V., Diagnoses of internal faults of threephase squirrel cage induction motor, in International Conference on Advances in Energy Conversion Technologies (ICAECT)2014, IEEE.

[10]- Liang, B., Condition monitoring of three-phase induction motors, 2000, The University of Manchester.

[11]- Bowen, B., The Differences Between Submersible \& Immersible Motors, in pumps \& system 2014.

[12]- Hayri Arabaci, O.B. Analysis of Rotor Faults Effects on Submersible Induction Motor Efficiency. in World Congress on Engineering of Computer Science. 2013. San Francisco USA.

[13]- Bantelay, D.T., Investigating Water Supply System ElectroMechanical Equipments Problems: A Case Study of Ethiopia. journal of optimization in industrial Engineering, 2019. 12(2): p. 45-54.

[14]- Panlong ZHANG a*, T.C.b., Guochao WANG c, Changzheng PENG d, Ocean Economy and Fault Diagnosis of Electric Submersible Pump applied in Floating platform. International Journal ofe-Navigation and Maritime Economy, 2017: p. 37-43.

[15]- Abhay.Patil, A.D., Yi Chen Daniel Steck, Chang-rui Bai,Yiming Chen, Gerald Morrison, Mechanical Reliability of
Electrical Submersible Pumps. Chinese Journal of Turbomachinery, 2018. 60(5): p. 69-77.

[16]- Alvaro Jose Bazurto , E.C.Q., Rosaura Castrillon Mendoza, Causes and Failures Classification of Industrial Electric Motor, 2016, researchgate.

[17]- Neelam Mebala, R.D., motor current signature analysis and its applications in induction motor fault diagnosis. journal of system applications engineering \&development, 2007. 2(1).

[18]- Pratesh Jayaswal, A.K.W., and K. B. Mulchandani, Machine Fault Signature Analysis. International Journal of Rotating Machinery, 2008.

[19]- S. Nandi, H.A.T., X li, condition monitoring and fault diagnosis of electrical motors, in IEEE trans. Energy Convers2005. p. 719-729.

[20]- R. Sathish, R.D., P. Ganga, Analyzing and Detection of Rotor Faults in Squirrel Cage Induction Motor Drives Using MATLAB. International Journal of Advanced Research in Electrical, Electronics and Instrumentation Engineering, 2015. 4(6).

[21]- Yannis L. Karnavas, I.D.C., Andreas Vrangas Fault Diagnosis of Squirrel-Cage Induction Motor Broken Bars based on a Model Identification Method with Subtractive Clustering in IEEE 11th International Symposium on Diagnostics for Electrical Machines, Power Electronics and Drives (SDEMPED), 2017, IEEE Tinos, Greece. p. 304-310.

[22]- M S Kova, A.P., Diagnosis of Electric Submersuble centrifugal Pump, in IOP2018, IOP: saint Petersburg Russia.

[23]- Marché, V. Electric Rotating Machine Eccentricities Faults Analysis with Flux. 2017.

[24]- Kamal.A.Sanad 1, A.A.E.-S., Dina Mourad Study and Improvement of Submersible Motor Protection. International Journal of Engineering Inventions 2017. 6(10): p. 87-95. 